\title{
Cobalt Oxide Nanoparticles Supported on $\gamma$-Alumina as Catalysts in the Selective Oxidation of Alcohols in Aqueous Phase
}

\author{
Bahman Abbaszadeh, Amin Ebadi* and Shahab Eslami \\ Department of Chemistry, Kazerun Branch, Islamic Azad University, Kazerun, Iran \\ http://dx.doi.org/10.13005/bbra/2105
}

(Received: 02 February 2016; accepted: 04 April 2016)

\begin{abstract}
In this work, cobalt oxide nanoparticles supported on $\gamma$-alumina were prepared and were well characterized by scanning electron micrograph (SEM) and X-ray diffraction patterns. These were employed as catalysts for the oxidation of alcohols to aldehydes or ketones with tert-butylhydroperoxide (TBHP) and hydrogen peroxide $\left(\mathrm{H}_{2} \mathrm{O}_{2}\right)$ as the oxidant in the liquid phase. For these cobalt oxide nanoparticles supported on $\gamma$-alumina, acetonitrile as the solvent was employed. The research results showed that oxidant and the catalyst type influenced the conversion percent of alcohols oxidation. TBHP was found to be better oxidant than $\mathrm{H}_{2} \mathrm{O}_{2}$ since higher conversion percent of alcohols were observed when TBHP was employed. The catalytic activity of $10 \% \mathrm{Co}_{3} \mathrm{O}_{4} /$ nano- $\gamma$-alumina was superior to that of $5 \%$ and $15 \% \mathrm{Co}_{3} \mathrm{O}_{4} /$ nano- $\gamma$-alumina catalysts. Under the optimum reaction conditions, the catalytic system of $10 \% \mathrm{Co}_{3} \mathrm{O}_{4}$ nanoparticles supported on $\gamma$ alumina gave about $\mathbf{8 2 . 3} \%$ conversion percent of cyclohexanol.
\end{abstract}

Key words: Oxidation, $\gamma$-Alumina, Nanoparticles, $\mathrm{Co}_{3} \mathrm{O}_{4}$, Alcohols.

Oxidation reactions are among the most important transformations in synthetic chemistry and offer an important methodology for the introduction and modification of functional groups. Therefore, the oxidation of alcohols by metal oxides to the corresponding carbonyl compounds is a worthwhile goal ${ }^{1,2}$. In this way, chemists have used different kinds of metal salts and oxides in the form of homogeneous catalysts 3,4 or supported metal ions and supporting oxometal catalysts as heterogeneous systems ${ }^{5,6}$.

Many different oxidants were used for the oxidation of alcohols such as pyridinium chlorochromate (PCC), pyridinium dichromate (PDC), $\mathrm{KMnO}_{4}, \mathrm{MnO}_{2}, \mathrm{CrO}_{3}$ and so on. Most of these oxidizing reagents which can be used in a research laboratory in stoichiometric amounts are expensive or toxic ${ }^{1,7}$. Thus, the advantages of

\footnotetext{
* To whom all correspondence should be addressed. Tel: +98 721 2230505; Fax: +98 721 2230508; E-mail: ebadiamin88@yahoo.com
}

environmentally friendly oxidizing agents, such as $\mathrm{H}_{2} \mathrm{O}_{2}$ and $\mathrm{O}_{2}$, have been extensively studied. $\mathrm{H}_{2} \mathrm{O}_{2}$ is attractive for producing active oxidation species in aqueous solution, with $\mathrm{H}_{2} \mathrm{O}$ as a by-product.

Supported metal oxide catalysts are frequently used as catalysts in partial oxidation reactions $^{8-10}$. In these catalysts, $\mathrm{Al}_{2} \mathrm{O}_{3}, \mathrm{TiO}_{2}, \mathrm{SiO}_{2}$ and $\mathrm{ZrO}_{2}$ are commonly used as the supports. Bulk oxides in general cannot be used in industrial processes as they impart poor thermal stability that lead to fast deactivation of the catalyst. Furthermore, it is also known that bulk $\mathrm{Co}_{3} \mathrm{O}_{4}$ leads to high combustion of organic molecules to carbon oxides ${ }^{11}$. Santra et al. ${ }^{12}$ have studied the oxidation of benzyl alcohol with molecular oxygen in the presence of gold nanoparticles on mesoporous cerium-tin mixed oxide as catalyst. In another report, Tian and coworkers have employed $\mathrm{RuO}_{2} / \mathrm{TiO}_{2}$ nanobelt heterostructures for gas-phase selective oxidation of benzyl alcohol. The $\mathrm{RuO}_{2} / \mathrm{TiO}_{2}$ samples exhibited good activity for oxidation of benzyl alcohol ${ }^{13}$. However, to the best of our 
knowledge, there is no report for application of $\mathrm{Co}_{3} \mathrm{O}_{4}$ nanoparticles supported on $\gamma$-alumina for partial oxidation of alcohols with $\mathrm{H}_{2} \mathrm{O}_{2}$ and TBHP. In this work we report $\mathrm{Co}_{3} \mathrm{O}_{4}$ nanoparticles supported on $\gamma$-alumina as catalysts for partial oxidation of alcohols to the corresponding carbonyl compounds in the liquid phase.

\section{EXPERIMENTAL}

\section{Instrument and Reagents}

Powder X-ray diffractions were performed by a Siemens D 5000. Specific surface area was measured by BET techniques in liquid $\mathrm{N}_{2}$ temperature by a Strohlien. The surface morphology of the samples was obtained using a Jeol-JSM-5610 LV scanning electron microscopes (SEM). The reaction products of oxidation were identified by GC-MS (Finnigan TSQ-7000) and were analyzed by GC (Shimadzu 8A). All the reagents were commercial grade obtained from Merck. None of the oxidation products were found in the alcohols before the oxidation reaction.

\section{Preparation of the Catalysts}

Aluminum nitrate $\left\{\mathrm{Al}\left(\mathrm{NO}_{3}\right)_{3} \cdot 9 \mathrm{H}_{2} \mathrm{O}\right\}$, aqueous ammonia $\left\{\mathrm{NH}_{3} \cdot \mathrm{H}_{2} \mathrm{O}\right\}$ and deionized water were used as starting chemicals. Two hundred milliliters of deionized water was taken in a 21 capacity round-bottom flask and stirred well using magnetic stirrer. Then, aluminum nitrate $(1.5 \mathrm{M})$ solution and $(10.4 \mathrm{M})$ solution of aqueous ammonia were added to $200 \mathrm{ml}$ of deionized water drop by drop to precipitate $\mathrm{Al}$ cations in the form of hydroxides. The temperature was maintained $\sim 55$ ${ }^{\circ} \mathrm{C}$ during precipitation/digestion experiment. The $\mathrm{pH}$ after precipitation was found to be in the range of 5.4-6.4. The precipitates were further digested at $55^{\circ} \mathrm{C}$ for $1 \mathrm{~h}$. After the alumina gel was formed, it was filtered and washed by distilled water. Then, $(0.5 \mathrm{M})$ cobalt nitrate $\mathrm{Co}\left(\mathrm{NO}_{3}\right)_{2}$ aqueous solution was added to the alumina-gel. This gel was stirred and homogenized and was placed in an oven under temperature of $100{ }^{\circ} \mathrm{C}$ for $24 \mathrm{~h}$. The mixture was then heated $2{ }^{\circ} \mathrm{C} / \mathrm{min}$ till the temperature reached $600^{\circ} \mathrm{C}$ and the mixture was kept at this temperature for $4 \mathrm{~h}$.

\section{Experimental Procedure}

In a typical procedure, a mixture of $0.2 \mathrm{~g}$ catalyst, $15 \mathrm{ml}$ solvent and $20 \mathrm{mmol}$ cyclohexanol was stirred under nitrogen in a $100 \mathrm{ml}$ round bottom flask equipped with a condenser and a dropping funnel at room temperature for $30 \mathrm{~min}$. Then 15 mmol of TBHP (solution $80 \%$ in di-tertbutylperoxide) or $\mathrm{H}_{2} \mathrm{O}_{2}\left(30 \%\right.$ in $\left.\mathrm{H}_{2} \mathrm{O}\right)$ was added as oxidizing reagents. The resulting mixture was then refluxed for $6 \mathrm{~h}$ under $\mathrm{N}_{2}$ atmosphere. After filtration, the solid was washed with solvent and then the reaction mixture was analyzed by GC. Products identification was done with GC-MS and confirmed by comparison of their retention times with authentic commercial samples of these compounds.

\section{RESULTSAND DISCUSSION}

\section{Characterization of the Catalysts}

The XRD pattern presented in Figure 1 indicates that $\gamma$-alumina nanoparticles are formed. There is no significant change in the $\mathrm{XRD}$ pattern with $10 \mathrm{wt} . \% \mathrm{Co}_{3} \mathrm{O}_{4}$ nanoparticles supported on $\gamma$ alumina which confirms that $\mathrm{Co}_{3} \mathrm{O}_{4}$ dispersed through pores does not change the $\gamma$-alumina structure.

Scanning electron micrograph (SEM) of a typical sample of $10 \% \mathrm{Co}_{3} \mathrm{O}_{4} /$ nano- $\gamma$-alumina is shown in Figure 2. It is clarified from Figure 2 that the sizes of the particles are in the ranges of $40-80$ $\mathrm{nm}$. This result was coincident with the particle sizes calculated from the Scherrer equation. Similar images were obtained for the other catalysts. Specific surface area measured with BET method was $186 \mathrm{~m}^{2} / \mathrm{g}$ for $\gamma$-alumina and $164 \mathrm{~m}^{2} / \mathrm{g}$ for $10 \%$ $\mathrm{Co}_{3} \mathrm{O}_{4} /$ nano- $\gamma$-alumina. This reduction in specific surface area for the supported $\mathrm{Co}_{3} \mathrm{O}_{4}$ may be an indication of encapsulation of $\mathrm{Co}_{3} \mathrm{O}_{4}$ in the nano$\gamma$-alumina pores.

\section{Catalytic Oxidation of Cyclohexanol}

The use of TBHP as an oxidant was based on the earlier studies on the oxidation of alcohols ${ }^{14}$, this oxidant was found to cause minimal destruction of the cobalt oxide catalysts, and to give better activity of the catalysts. The performance of the set of samples prepared as catalysts for the oxidation of alcohols was tested with TBHP. The solvent of acetonitrile was employed for the catalysis, since all the reagents dissolved and gave the highest yields of the products. At first, the reactivity of a model compound, cyclohexanol, was examined under a variety of experimental condition (Table 1). In all reactions were produced only one 
Table 1. Results of the cyclohexanol oxidation using $\mathrm{Co}_{3} \mathrm{O}_{4} /$ nano- $\gamma$-alumina as catalysts

\begin{tabular}{lccc}
\hline Catalyst & Oxidant & $\begin{array}{c}\text { Conversion } \\
\text { (\%) cyclohexanol }\end{array}$ & $\begin{array}{c}\text { Product selectivity } \\
\text { (\%) cyclohexanone }\end{array}$ \\
\hline $5 \% \mathrm{Co}_{3} \mathrm{O}_{4} / \gamma-\mathrm{Al}_{2} \mathrm{O}_{3}$ & $\mathrm{H}_{2} \mathrm{O}_{2}$ & 53.2 & 100 \\
$5 \% \mathrm{Co}_{3} \mathrm{O}_{4} / \gamma-\mathrm{Al}_{2} \mathrm{O}_{3}$ & $\mathrm{TBHP}_{2}$ & 64.7 & 100 \\
$10 \% \mathrm{Co}_{3} \mathrm{O}_{4} / \gamma-\mathrm{Al}_{2} \mathrm{O}_{3}$ & $\mathrm{H}_{2} \mathrm{O}_{2}$ & 69.7 & 100 \\
$10 \% \mathrm{Co}_{3} \mathrm{O}_{4} / \gamma-\mathrm{Al}_{2} \mathrm{O}_{3}$ & $\mathrm{TBHP}$ & 82.3 & 100 \\
$15 \% \mathrm{Co}_{3} \mathrm{O}_{4} / \gamma-\mathrm{Al}_{2} \mathrm{O}_{3}$ & $\mathrm{H}_{2} \mathrm{O}_{2}$ & 61.8 & 100 \\
$15 \% \mathrm{Co}_{3} \mathrm{O}_{4} / \gamma-\mathrm{Al}_{2} \mathrm{O}_{3}$ & $\mathrm{TBHP}_{3}$ & 72.5 & 100 \\
$\gamma-\mathrm{Al}_{2} \mathrm{O}_{3}$ & $\mathrm{H}_{2} \mathrm{O}_{2}$ & 21.8 & 100 \\
$\gamma-\mathrm{Al}_{2} \mathrm{O}_{3}$ & $\mathrm{TBHP}$ & 25.6 & \\
\hline
\end{tabular}

Reaction condition: 0.2 g catalyst, cyclohexanol 20 mmol, oxidant $15 \mathrm{mmol}$, solvent of acetonitrile, reflux temperature, reaction time $6 \mathrm{~h}$.

Table 2. Effect of the $10 \% \mathrm{Co}_{3} \mathrm{O}_{4} /$ nano- $\gamma$-alumina catalyst in the oxidation of different alcohols

\begin{tabular}{lccc}
\hline Alcohols & Conversion (\%) & Selectivity (\%) & Products \\
\hline 2-Propanol & 75.3 & 100 & 2-Propanon \\
Benzyl alcohol & 71.8 & 100 & Benzaldehyde \\
Isobutylalcohol & 66.9 & 100 & Isobutanal \\
1-Butanol & 58.4 & 100 & 1-Butanal \\
\hline
\end{tabular}

product (cyclohexanone) therefore, selectivity (\%) is 100 with respect to it. The research results showed that three kinds of catalysts could catalyze cyclohexanol oxidation with TBHP. The activity of the catalysts was as follows: $10 \% \mathrm{Co}_{3} \mathrm{O}_{4} /$ nano- $\gamma$ alumina $>15 \% \mathrm{Co}_{3} \mathrm{O}_{4} /$ nano- $\gamma$-alumina $>5 \% \mathrm{Co}_{3} \mathrm{O}_{4} /$ nano- $\gamma$-alumina. In the presence of $10 \% \mathrm{Co}_{3} \mathrm{O}_{4} /$ nano- $\gamma$-alumina, conversion percentage of cyclohexanol was $82.3 \%$ with TBHP as an oxidant and acetonitrile as the solvent. Contrastive experiment results show that cyclohexanol oxidation with TBHP did not occur in the absence of the catalyst under the same reaction condition. In addition, unsupported $\gamma$-alumina has shown lower catalytic activity than the supported catalyst.

Influences of Reaction Time on Cyclohexanol Oxidation Reaction

In this experiment, the change in conversion percentage of cyclohexanol in the presence of tert-butylhydroperoxide oxidant and $10 \% \mathrm{Co}_{3} \mathrm{O}_{4}$ /nano- $\gamma$-alumina catalyst was monitored and plotted with respect to time (Figure 3). The reaction was carried out at reflux temperature for 6 h with $0.2 \mathrm{~g}$ catalyst and $20 \mathrm{mmol}$ cyclohexanol

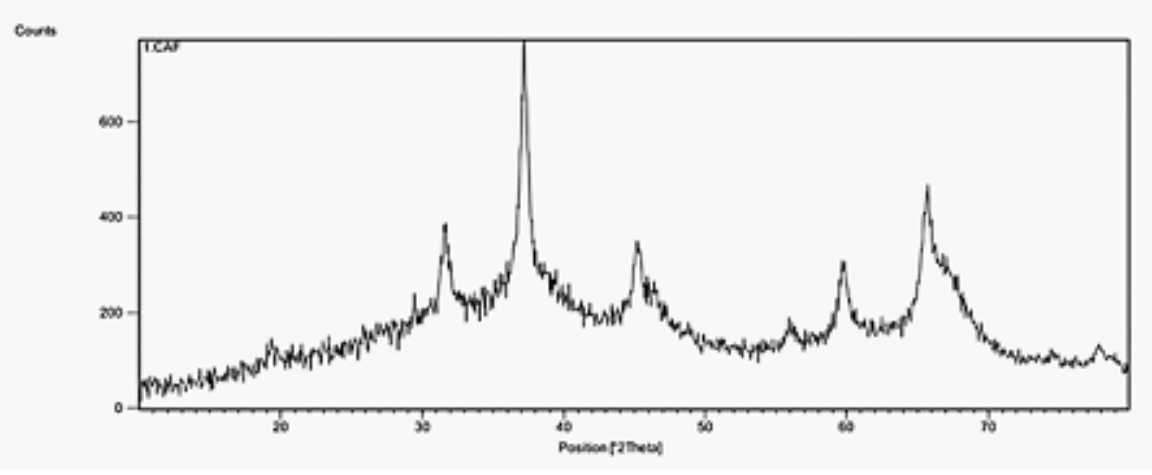

Fig. 1. XRD patterns of 10 wt. $\% \mathrm{Co}_{3} \mathrm{O}_{4} /$ nano- $\gamma$-alumina 
and $15 \mathrm{mmol}$ TBHP in a round bottom flask and some samples was drawn out at regular intervals and analyzed by GC. Figure 3 shows that the conversion of cyclohexanol increases continuously until $82.1 \%$ as time increases and

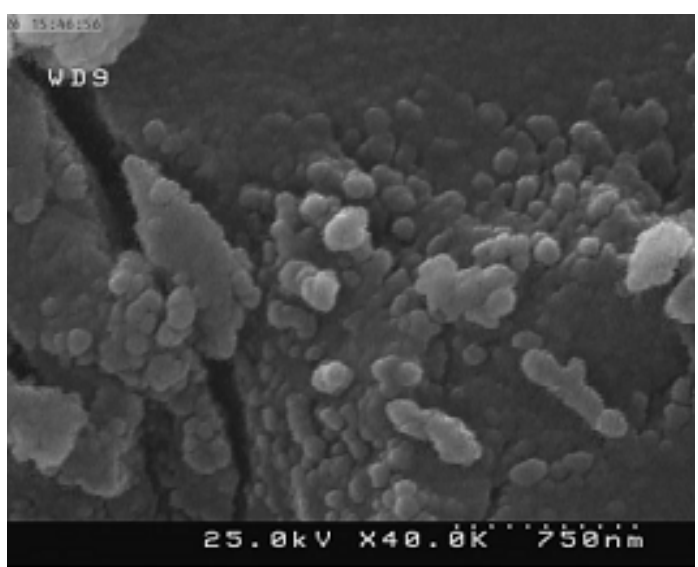

Fig. 2. SEM photograph of $10 \% \mathrm{Co}_{3} \mathrm{O}_{4} /$ nano- $\gamma$-alumina

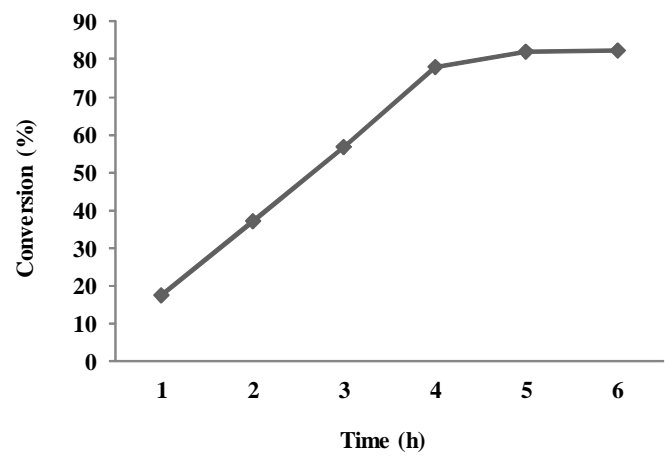

Fig. 3. The effect of reaction time on cyclohexanol conversion

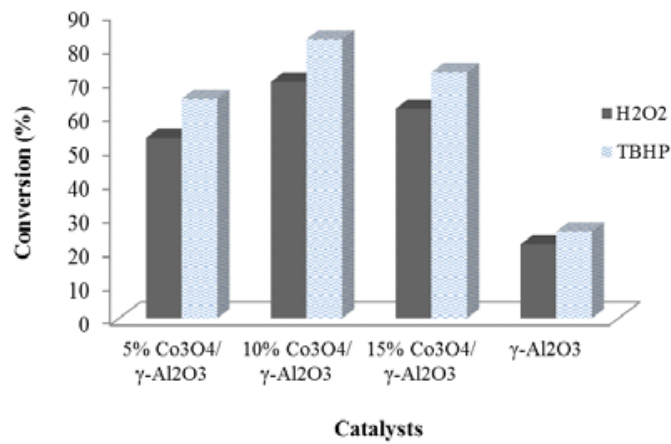

Fig. 4. The effect of oxidant type on cyclohexanol conversion in the presence of acetonitrile as the solvent. then remains constant after $5 \mathrm{~h}$, therefore duration about $5-6 \mathrm{~h}$ is proper reaction time.

Influences of the Loading Amount of Cobalt Oxide on Cyclohexanol Oxidation Reaction

For investigation of the loading effect $\mathrm{Co}_{3} \mathrm{O}_{4}$ on the conversion and selectivity of the products three catalysts were tested. In Table 1 , details of the conversion and selectivity of the products for each catalyst are shown. It is observed that maximum conversion occurs with the catalyst of $10 \% \mathrm{Co}_{3} \mathrm{O}_{4} /$ nano- $\gamma$-alumina. It is known that cobalt oxide can be highly dispersed on $\gamma$-alumina at $10 \mathrm{wt} . \%$ loading. A drop of conversion of cyclohexanol of the catalyst with higher loadings than $10 \mathrm{wt} . \%$ is possibly due to a more reduction of the specific surface area of the catalyst. Under these reaction conditions, the order of catalytic activities is as follows:

$10 \% \mathrm{Co}_{3} \mathrm{O}_{4} /$ nano- $\gamma$-alumina $>15 \% \mathrm{Co}_{3} \mathrm{O}_{4} /$ nano- $\gamma$ alumina $>5 \% \mathrm{Co}_{3} \mathrm{O}_{4} /$ nano- $\gamma$-alumina.

\section{Influences of Substrates and Oxidant Type on} Cyclohexanol Oxidation Reaction

Figure 4 shows that the reactivity of the cyclohexanol toward oxidation with TBHP and $\mathrm{H}_{2} \mathrm{O}_{2}$ on $\mathrm{Co}_{3} \mathrm{O}_{4}$ nanoparticles supported on $\gamma$ alumina catalysts depend on type of oxidant. tertbutylhydroperoxide (TBHP) was found to be a more convenient oxidizing reagent due to weaker $\mathrm{O}-\mathrm{O}$ bond than hydrogen peroxide $\left(\mathrm{H}_{2} \mathrm{O}_{2}\right)$.

In this study, experiments on various selected alcohols were performed and the comparisons with respect to conversion and product selectivity are represented in Table 2 . Higher conversion was obtained for cyclohexanol on $10 \% \mathrm{Co}_{3} \mathrm{O}_{4} /$ nano- $\gamma$-alumina catalyst using tertbutylhydroperoxide oxidant. Table 2 shows that the reactivity of the alcohols toward oxidation with TBHP and $\mathrm{H}_{2} \mathrm{O}_{2}$ on $10 \% \mathrm{Co}_{3} \mathrm{O}_{4}$ /nano- $\gamma$-alumina catalyst depends on the particular structure of the substrate.

\section{CONCLUSION}

In this study, a $\gamma$-alumina was prepared, and then its role in the catalytic activity of the cobalt oxide nanoparticle in the oxidation reaction of cyclohexanol in the liquid phase was investigated. The characteristics of catalysts that were prepared using the XRD, SEM and BET were investigated. In addition, the catalytic activity of 
the cobalt oxide nanoparticles supported on $\gamma$ alumina in oxidation of cyclohexanol with tertbutylhydroperoxide (TBHP) as well as hydrogen peroxide $\left(\mathrm{H}_{2} \mathrm{O}_{2}\right)$ as the oxidant and in the liquid phase were studied which revealed that TBHP oxidant was better than $\mathrm{H}_{2} \mathrm{O}_{2}$. In addition, methanol, ethanol and acetonitrile were used as the solvent. Due to its high polarity and the creation of reactive oxygen species in the reaction medium, acetonitrile was far better than other solvents. Finally, the oxidation of different alcohols was analyzed using optimum conditions that became clear that various alcohols showed different percentage of conversion that was based on the type of alcohols structure.

\section{ACKNOWLEDGEMENTS}

We gratefully acknowledge financial support from the Research Council of kazerun Branch, Islamic Azad University.

\section{REFERENCES}

1. He, Y., Ma, X., Lu, M., Oxidation of alcohols with hydrogen peroxide in the presence of a new triple-site phosphotungstate, Arkivoc, 2012; 8: 187-197.

2. Rezaeifard, A., Jafarpour, M., Naeimi, A., Mehri, S., Efficient and highly selective aqueous oxidation of alcohols and sulfides catalyzed by reusable hydrophobic copper (II) phthalocyanine, Inorg. Chem. Commun., 2012; 15: $230-4$.

3. Sugimoto, H., Sawyer, D.T., Ferric chloride induced activation of hydrogen peroxide for the epoxidation of alkenes and monoxygenation of organic substrates in acetonitrile, J. Org. Chem., 1985; 50: 1784-6.

4. Lorber, C.Y., Osborn, J.A., Cisdioxomolybdenum(VI) complexes as new catalysts for the Meyer-Schuster rearrangement, Tetrahedron Lett., 1996; 37: 853-6.

5. Turk, H., Ford, W.T., Autoxidation of 2,6-di- tert-butylphenol in water catalyzed by cobalt phthalocyaninetetrasulfonate bound to polymer colloids, J. Org. Chem., 1988; 53(2): 460-2.

6. Pinnavia, T.J., Tzou, M.S., Landau, S.D., New chromia pillared clay catalysts, J. Am. Chem. Soc., 1985; 107(16): 4783-5.

7. Sandra, E., Garrone, M., Garrone, A., Efficient solvent-free iron (III) catalyzed oxidation of alcohols by hydrogen peroxide, Tetrahedron Lett., 2003; 44(3): 549-552.

8. Mamedov, E.A., Corberan, V.C., Oxidative dehydrogenation of lower alkanes on vanadium oxide-based catalysts. the present state of the art and outlooks, Appl. Catal. A: Gen., 1995; 127(1-2): 1-40

9. Deo, G., Wachs, I.E., Haber, J., Supported vanadium-oxide catalysts - molecular structural. characterization and reactivity properties, Crit. Rev. Surf. Chem., 1994; 4(3/4): 141-187.

10. Sanati, M., Andersson, A., Kinetics and mechanisms in the ammoxidation of toluene over a titania (B)-supported vanadium oxide monolayer catalyst. 1 . selective reactions, Ind. Eng. Chem. Res., 1991; 30(2): 312-320.

11. Routray, K., Reddy, K.R.S.K., Deo, G., Oxidative dehydrogenation of propane on $\mathrm{V}_{2} \mathrm{O}_{5} /$ $\mathrm{Al}_{2} \mathrm{O}_{3}$ and $\mathrm{V}_{2} \mathrm{O}_{5} / \mathrm{TiO}_{2}$ catalysts: understanding the effect of support by parameter estimation, Appl. Catal. A: Gen., 2004; 265(1): 103-113.

12. Santra, Ch., Pramanik, M., Bando, K., Maity, S., Chowdhury, B., Gold nanoparticles on mesoporous cerium-tin mixed oxide for aerobic oxidation of benzyl alcohol, J. Mol. Catal. A: Chem., 2016; 418-419: 41-53.

13. Tian, J., Hu, X., Wei, N., Zhou, Y., Xu, X., Cui, H., Liu, H., $\mathrm{RuO}_{2} / \mathrm{TiO}_{2}$ nanobelt heterostructures with enhanced photocatalytic activity and gas-phase selective oxidation of benzyl alcohol, Solar Energy Mat. Solar Cells, 2016; 151: 7-13.

14. Grootboom, N., Nyokong, T., Iron perchlorophthalocyanine and tetrasulfophthalocyanine catalyzed oxidation of cyclohexane using hydrogen peroxide, chloroperoxybenzoic acid and tertbutylhydroperoxide as oxidants, J. Mol. Catal. A: Chem., 2002; 179(1-2): 113-123. 